\title{
Design of fractional order PID controller for AVR system using whale optimization algorithm
}

\author{
Layla H. Abood, Bashra Kadhim Oleiwi
}

Department of Contol and System Engineering, University of Technology, Iraq

\begin{tabular}{l} 
Article Info \\
\hline Article history: \\
Received Mar 22, 2021 \\
Revised Jul 24, 2021 \\
Accepted Jul 28, 2021 \\
\hline
\end{tabular}

Keywords:

AVR system

Fractional order controllers Whale optimization algorithm

\begin{abstract}
In this paper a robust fractional order PID (FOPID) controller is proposed to control the automatic voltage regulator (AVR) system, the tuning of the controller gains are done using whale optimization algorithm (WOA) and integral time absolute error (ITAE) cost function is adopted to achieve an efficient performance. The transient analysis was done and compared with conventional PID in terms of overshoot, settling time, rise time, and peak time to explain the superiority of the proposed controller. Finally, a robustness analysis is done by adding external disturbances to the system and changing the system parameters by $\pm 20 \%$ from its original value, the controller overcomes the disturbances signals with less than $0.25 \mathrm{~s}$ and faces the changes of the system values and returning the response within (0.7-1) sec and led the system to the desired response efficiently. The numerical simulations showed that the smart WOA offers satisfying results and faster response reflected clearly on the robust and stable performance of the proposed controller in improving the transient analysis of AVR system response.
\end{abstract}

This is an open access article under the CC BY-SA license.

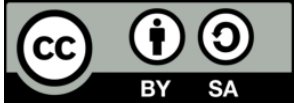

\section{Corresponding Author:}

Layla H. Abood

Department of Control and System Engineering

University of Technology

Baghdad, Iraq

Email: 60066@uotechnology.edu.iq

\section{INTRODUCTION}

The system of supplying power network voltages has a nominal value level. Any difference in this supplied voltage value will cause an influence in the dynamics of all power networks distributed. This case of changing values will reflect on the system's performance and its longevity. The effect will appear clearly on the power and finally on the real system supplying desired voltages. To overcome this matter, an automatic voltage regulator (AVR) is applied [1], [2]. As its name referring, AVR is a device used in generation stations that support the voltage value levels as wanted values in spite of any variation that may occurr by stabilizing the voltage value in the excitation part, then controlling excitation voltage value will lead to regulate the output generating voltage as desired values to achieve a stable and reliable voltage supplying system [3].

The AVR suffers from some points that appeared in its output response like oscillation, overshoot, and an error in its value in the steadystate, so for solving all these points a closed loop with an efficient controller will remove these undesired values so it can be seen that many researchers proposed different controlling approaches to reach to stability in response and robustness in the behavior of AVR system [4], like using the classical PID controller with new optimization method to tune its gain for reaching to accurate and suitable value that drives stable response, in [5] researcher apply three optimization method whale 
optimization (WO), symbiotic organism search (SOS), particle swarm optimization (PSO) and finally hybrid between PSO-SOS tuning methods, finally compared between all these methods to choose the best of them also in [6]-[9] the PID controller with different optimization method is used to tune the gains for a stable desired response, while in [10]-[14] suggest a controller with an improvement in its structure depending on the mathematics of fractional calculus called fractional order PID (FOPID) which achieve efficient response as compared with other controllers. In [15] a combination between Fuzzy and PID controller is applied in a way of combine fuzzy with proportional (FP) and fuzzy with integration (FI) and fuzzy with differential (FD) to be $(\mathrm{FP}+\mathrm{FI}+\mathrm{FD})$, then for reaching robust response a genetic algorithm $(\mathrm{GA})$ is combined with and PSO (HGAPSO) is adopted while in [16] a two robust method is used to regulate the AVR response, fuzzy and fuzzy type 2 with PI controller is proposed then used different tuning methods to adjust the values of the controller gains to achieve stable response and finally compare between them to find the suitable way that achieves robustness and fast desired response.

The contribution of this paper is the use of WOA for tuning of FOPID controller parameters. This method has a unique and smart search analysis also have less parameter when applied then give fast and accurate results of FOPID controller parameters, also the FOPID controller with its five design criteria $\left(K_{\mathrm{P}}, K_{\mathrm{I}}, K_{\mathrm{D}}, \lambda, \mu\right)$ give a high degree of freedom when tunning its parameters then the characteristics of time response for FOPID controller is compared with classical PID controller and with other controllers tuned with different optimization methods, finally discuss the controller robustness based on parameter uncertainty and external disturbances. The rest of this paper is arranged as shown in: Section 2 presents the modeling of the AVR system, Section 3 explains the FOPID controller and in Section 4 the proposed WOA method is demonstrated. Section 5 a simulation and discussion results are reported and in Section 6 a robustness analysis is explained and finally, in Section 7 a conclusion of the study is discussed.

\section{AVR SYSTEM MODELING}

The AVR system comprises of four parts with names amplifier, exciter, generator, and sensor parts all these parts consist of a transfer function with first order type as indicated in Figure 1. The parameters (T and k) are the time and gain constants that are known for each transfer functions part of the AVR system. The values of these constants used in this study are listed in Table 1 [17]-[19]:

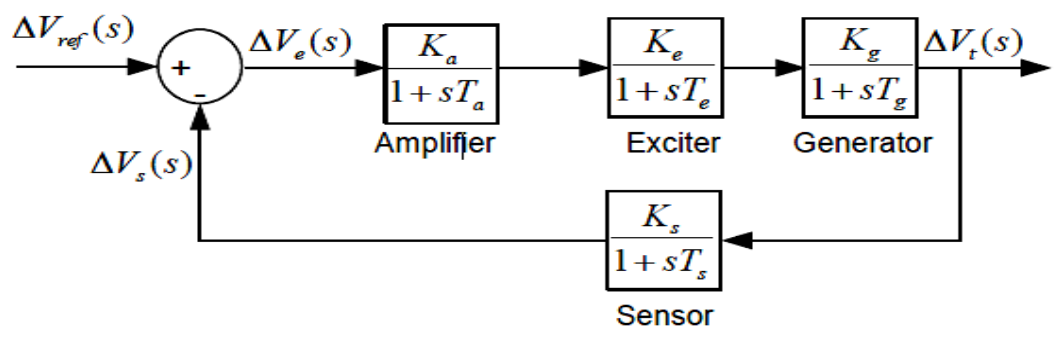

Figure 1. AVR system block diagram

Table 1. The performance values of AVR parts

\begin{tabular}{ccc}
\hline AVR Part & Parameter & Value \\
\hline Amplifier & $\mathrm{Ka}$ & 10.0 \\
& $\mathrm{Ta}$ & 0.1 \\
Exciter & $\mathrm{Ke}$ & 1 \\
& $\mathrm{Te}$ & 0.4 \\
Generator & $\mathrm{Kg}$ & 1 \\
& $\mathrm{Tg}$ & 1 \\
Sensor & $\mathrm{Ks}$ & 1 \\
& $\mathrm{Ts}$ & 0.01 \\
\hline
\end{tabular}

Then the closed loop transfer function will be [5]:

$$
\frac{\Delta V t(s)}{\Delta \operatorname{Vref}(s)}=\frac{0.1 s+10}{0.0004 s^{4}+0.0454 s^{3}+0.555 s^{2}+1.51 s+11}
$$




\section{FRACTIONAL ORDER PID CONTROLLER}

This controller is an enhanced form of classical PID controller because it depends on the fractional value of two PID parameters (derivative and integral) instead of integer values, this fractional parameter is $(\mu$ and $\lambda$ ) due to this the tuning parameter will be five instead of three, the extra parameters will ensure robustness in the response of the system and improve its performance. The transfer function of the FOPID controller will be as shown:

$$
G_{\mathrm{FOPID}}=K_{\mathrm{P}}+K_{\mathrm{I}} \frac{1}{s^{\lambda}}+s^{\mu} K_{\mathrm{D}}
$$

The tunning parameters will be $\left(K_{\mathrm{P}}, K_{\mathrm{I}}, K_{\mathrm{D}}, \lambda, \mu\right)$. The value of the two fractional parameters $\lambda$ and $\mu$ can be real or integers., if $\lambda=1, \mu=1$ then a classical PID is obtained but if one of them is 1 and the other is 0 then it be a classical PI controller (if $\lambda=1, \mu=0$ ) and classical PD controller (if $\lambda=0, \mu=1$ ) respectively. The FOPID controller block diagram is explained in Figure 2 [20], [21].

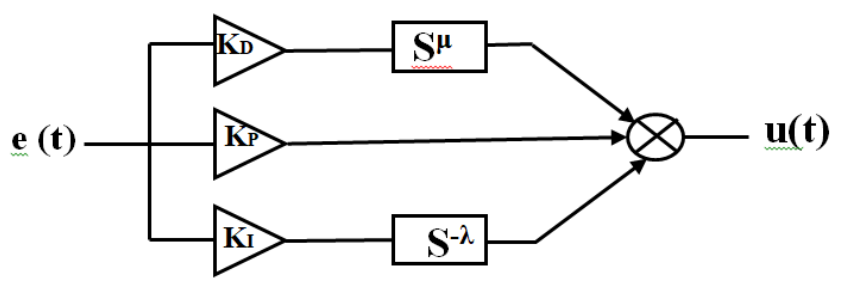

Figure 2. FOPID controller block diagram

\section{WHALE OPTIMIZATION ALGORITHM}

The wle optimization algorithm is an intelligent method presented by Mirjilili and Lewis [22], [23], it translates the biological behavior of whales when finding their prey, they have a special strategy in hunting the small fishes on the sea surface by generating specific bubbles with a circular path then the hunting process is done in three steps as shown in: 1-Encircling pray: The whale can specify the area of the prey and then start to encircle them. WOA cannot expect the place directly, the WOA expects that the optimum path obtained for finding the prey so far is the optimal solution or nearby, then the other whales try to update their places based on prey location (best path found). This step is described as shown:

$$
\begin{aligned}
& \vec{D}=\left|\vec{C} \cdot \overrightarrow{X^{*}}-\vec{X}(t)\right| \\
& \vec{X}(t+1)=\overrightarrow{X^{*}}(t)-\vec{A} \cdot \vec{D}
\end{aligned}
$$

The relation for calculate the coefficient vectors $\vec{A}$ and $\vec{C}$ are:

$$
\begin{aligned}
& \vec{A}=2 \vec{a} \cdot \vec{r}-\vec{a} \\
& \vec{C}=2 \cdot \vec{r}
\end{aligned}
$$

Where $\vec{r}$ is a random value vector $[0,1]$ and $\vec{a}$ has a value from 2 to 0 and it is reduced linearly during the iterations of the search. Various positions near the best position can be obtained based on $\vec{A}$ and $\vec{C}$ vectors values then (4) can be updated by any agent near the current best position and the prey can be encircled. 2-Bubble-net hunting process: in this step, whales specify and attack their prey based on two approaches: the first one is encircling the prey in shrinking mechanism in which the $\vec{A}$ vector value is changed to find various near position toward the optimal whale path by changing $\vec{a}$ vector value, at this point shrinking the places of the whales toward optimal path is done. The second step is to simulate the mechanism of the bubble net attacking method, the algorithm adopts a spiral mechanism for updating places then finds the difference between prey place and other whale's places, and it is expressed mathematically as shown below:

$$
\vec{X}(t+1)=\overrightarrow{D^{\prime}} \cdot e^{b l} \cdot \operatorname{Cos}\left(2 \pi l+\overrightarrow{X^{*}}(t)\right.
$$


Where $D^{\prime}$ explain the difference between the prey place (nearest whale) and the ith one while b represents the logarithmic spiral shape and $l$ is a random value $[-1,1]$. Now to mimic the real behavior a probability of $50 \%$ is assumed to updates whales places (either shrinking or spiral) mechanism during the search iterations and it is expressed as shown below:

$$
\left\{\begin{array}{l}
\overrightarrow{X^{*}}(t)-\vec{A} \cdot \vec{D} \text { if } \mathrm{P}<0.5 \\
\vec{X}(t+1)= \\
\overrightarrow{D^{\prime}} \cdot e^{b l} \cdot \operatorname{Cos}\left(2 \pi l+\overrightarrow{X^{*}}(t) \text { if } \mathrm{P} \geq 0.5\right.
\end{array}\right.
$$

3-Prey search step: As explained in this algorithm whales have a special and unique method for attacking process, in the predation another specific agent will search randomly and the coefficient vector $\vec{A}$ value is assumed in the range [-1,1], different whales are compelled to search far from the reference whale to detect more prey. The updating process now is done based on the randomly new whale adopted and it can be expressed as shown:

$$
\begin{aligned}
& \vec{D}=\left|\vec{C} \cdot \overrightarrow{X_{\text {rand }}}-\vec{X}(t)\right| \\
& \vec{X}(t+1)=\overrightarrow{X_{\text {rand }}}-\vec{A} \cdot \vec{D}
\end{aligned}
$$

where $X_{\text {rand }}$ is a random whale obtained during the search process of the current population. The flowchart of WOA is explained in Figure 3 [24], [25]. WOA adopts a set of random nominee decisions (population) and utilizes three steps to update and modify the place of nominee decisions in each step, as explained above (Encircling, searching then finally spiral updating places), the first two steps depend on ( $\mathrm{P}$ and $|\mathbf{A}|)$ parameters and the final step depend only on $\mathrm{P}$ parameter to update its places to an optimal path in finding prey.

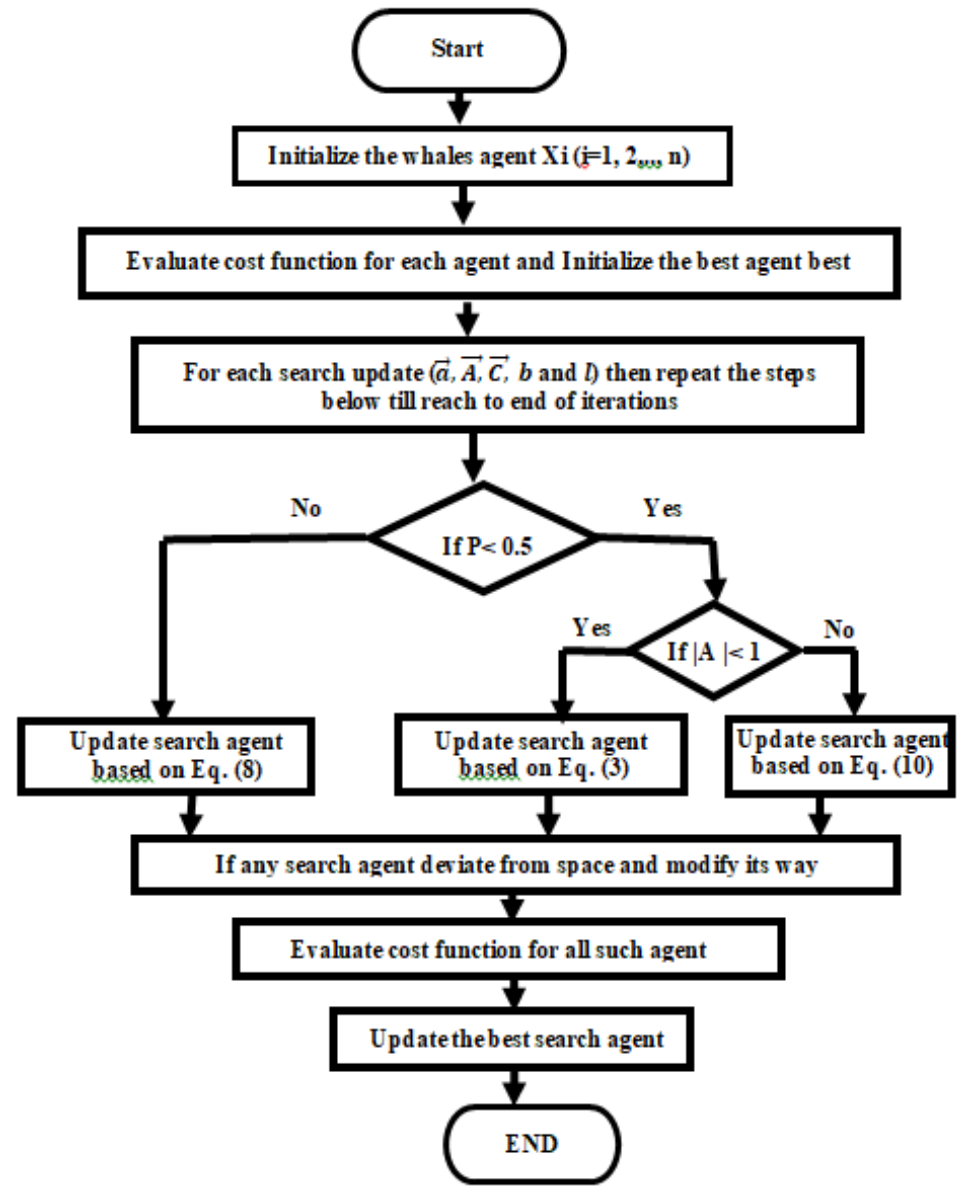

Figure 3. Flowchart of WOA algorithm 


\section{SIMULATION RESULTS}

In this section the simulation results for the proposed controller is presented, all simulation is done using MATLAB/Simulink to test the performance of the FOPID controller based on WOA then compare it with the classical PID controller which tuned using WOA also, the initial parameter of WOA is listed in Table 2.

Table 2. WOA Parameters

\begin{tabular}{lc}
\hline \multicolumn{1}{c}{ Description } & value \\
\hline No. Of population & 50 \\
Maximum number of iteration & 30 \\
Dimension & 5 \\
\hline
\end{tabular}

Then to test the performance of the controller in tracking desired output value, a performance index (fitness function) is used to test the error continuously. In this paper, integral time absolute error (ITAE) was adopted as a fitness function and it is shown in (11) [26], used in WOA to tune the controller gains and achieve stable system response, the fitness function for the system is indicated in Figure 4 and the block diagram of the system shown in Figure 5.

$$
\operatorname{ITAE}=\int_{0}^{\infty} t|\mathrm{e}| d t
$$

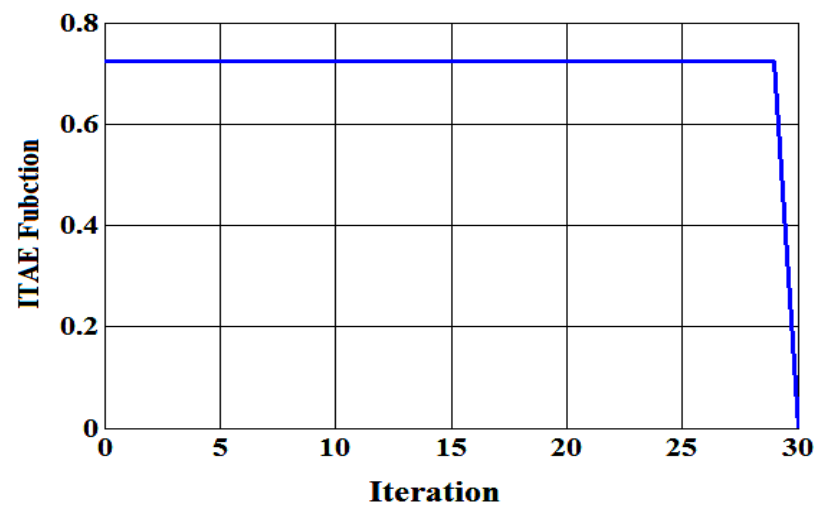

Figure 4. ITAE fitness function behavior for optimal FOPID controller

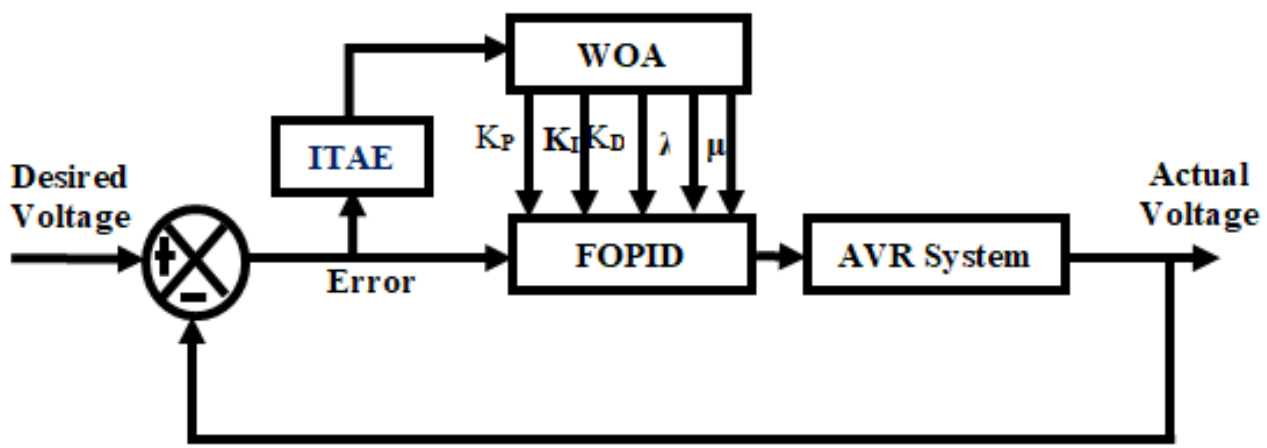

Figure 5. FOPID controller for AVR system based on WOA

To show the system performance based on optimal FOPID controller a comparison with classical PID is done (tuned using WOA also), Figure 6 indicates the system response for the optimal controllers PID and FOPID, and the gains of the optimal controllers are listed in Table 3. The step response results for the two controllers is shown in Table 4. 


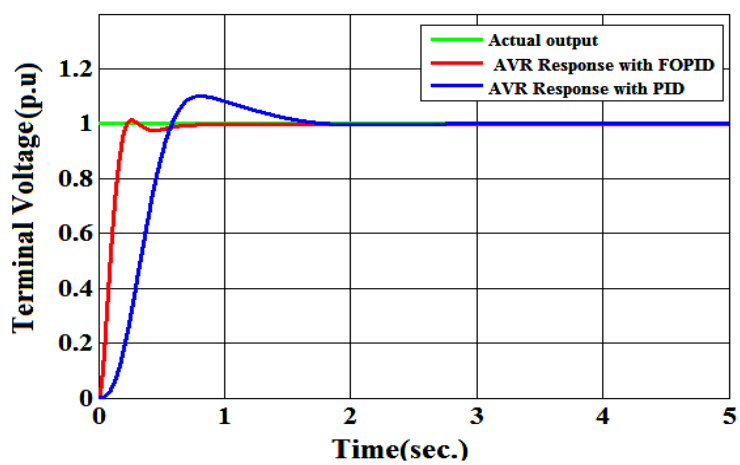

Figure 6. Terminal voltage responses for optimal controllers

Table 3. Optimal controllers Gains tuned using WOA

\begin{tabular}{lccccc}
\hline Controller & \multicolumn{5}{c}{ Controller Gains } \\
& $\mathrm{K}_{\mathrm{p}}$ & $\mathrm{K}_{\mathrm{I}}$ & $\mathrm{K}_{\mathrm{D}}$ & $\lambda$ & $\mu$ \\
\hline FOPID & 0.896 & 10.515 & 0.458 & 0.948 & 1.127 \\
PID & 0.9 & 4.113 & 0.387 & & \\
\hline
\end{tabular}

Table 4. Step response results for optimal controllers

\begin{tabular}{lcccc}
\hline Controller & Peak Time(s) & Rise Time(s) & Settleing Tim(s) & $\mathrm{M}_{\mathrm{p}(\%)}$ \\
\hline FOPID & 0.27 & 0.1405 & 0.213 & 1.28 \\
PID & 0.8 & 0.3455 & 0.557 & 11.38 \\
\hline
\end{tabular}

The difference between the proposed controller and classical PID controller appears in the step response analysis, this is due to the benefits of fractional mathematic effect on system response as shown it has fast settling time with $38 \%$ faster than the classical PID controller and the small overshoot (1.24) which achieve a stable and efficient desired response. In Table 5 a comparison with other controllers is explained based on parameters of response analysis, as shown from the analysis the FOPID controller is faster than PID [8], [9], fuzzy PI, and fuzzy 2 PI [15] controllers in tracking the desired value with faster settling time (0.213s) with small overshoot value but if compared with [6] it can be seen that it have very small overshoot value but also have slow settling time, the proposed FOPID is faster than [6] by nearly $47.25 \%$, this difference due to the smart WOA that tune the gains of the controller to optimum values then lead the system to reach to the desired response.

Table 5. Response analysis comparison with other controllers

\begin{tabular}{lccc}
\hline Optimization -Controller & $\begin{array}{c}\text { settling } \\
\text { time(s) }\end{array}$ & Rise time(s) & $\begin{array}{c}\text { Overshoot } \\
(\%)\end{array}$ \\
\hline WOA-PID & 0.557 & 0.3455 & 11.38 \\
SSA - PID[8] & 0.551 & 0.0981 & 15.5 \\
AEO-PID[9] & 1.0360 & 0.1065 & 22.677 \\
PSO -Fuzzy PI [15] & 1.275 & 0.537 & 0 \\
PSO -Fuzzy2 PI [15] & 1.358 & $0.529 \mathrm{~s}$ & 0 \\
CS- FOPID[6] & 0.4507 & 0.1042 & 0.0014 \\
Proposed WOA- FOPID & 0.213 & 0.1405 & 1.28 \\
\hline
\end{tabular}

To obtain the controller efforts for the two controllers (PID and FOPOID) the energy and maximum control signal is calculated as shown in Table 6, it explains that the FOPID controller has the highest control effort. It appears worst values but it is completely normal due to the fastest response as shown in Table 4 because the controller exerts more effort for giving a faster transient response while in PID controller which is low effort consuming, has the slowest response as indicated in the results obtained.

Table 6. Control effort analysisfor PID and FOPID controllers

\begin{tabular}{ccc}
\hline Controller & Energy & Umax \\
\hline PID & 76.11 & 382 \\
FOPID & 492.5 & 1135 \\
\hline
\end{tabular}




\section{ROBUSTNESS ANALYSIS}

Robustness analysis is done to check the system response based on two matters the first one is when the voltage is changed during working properly, it means there is a difference like more than needed desired value or less than it due to changing load or signal added or decreased from other devices, at this point the proposed controller must reject any external disturbances may face the system and save the desired value as needed. Figure 7 show the behavior of controller with negative and positive disturbance signal.

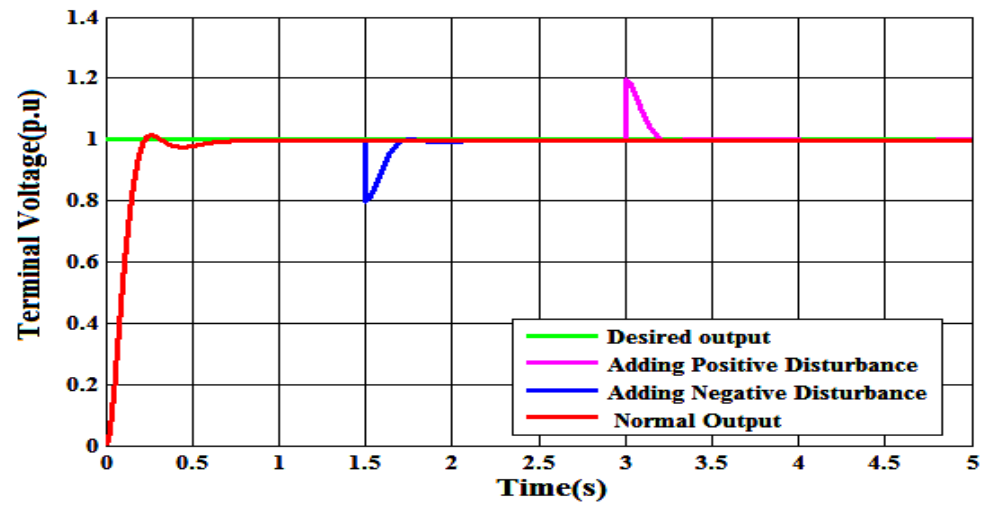

Figure 7. Response of AVR system with disturbance signals

As shown in Figure 7 the negative disturbance signal is added at time $1.5 \mathrm{~s}$ the response is affected but the controller returns the response to the desired value in a short period $(0.228 \mathrm{~s})$ then adding positive disturbance signal at time $3 \mathrm{~s}$ which also affected the response but the controller solves this deviation in the response within $0.213 \mathrm{~s}$ and reach to the desired value, this reflects the ability of the controller to overcome any noise may face the system and solve it within a short period. The second matter happens when the AVR system parameters are changed during working (it mean $\mathrm{K}$ and $\mathrm{T}$ ) for any parts that the AVR system consists of, here a change in the amplifier part is applied to the AVR system with $\pm 20 \%$ from its original value, Figure 8 explains the response of the controller based on the difference happened in the AVR system.

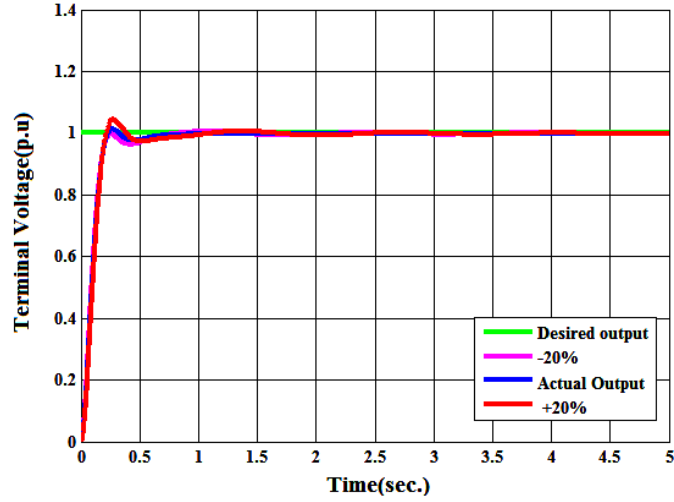

(a)

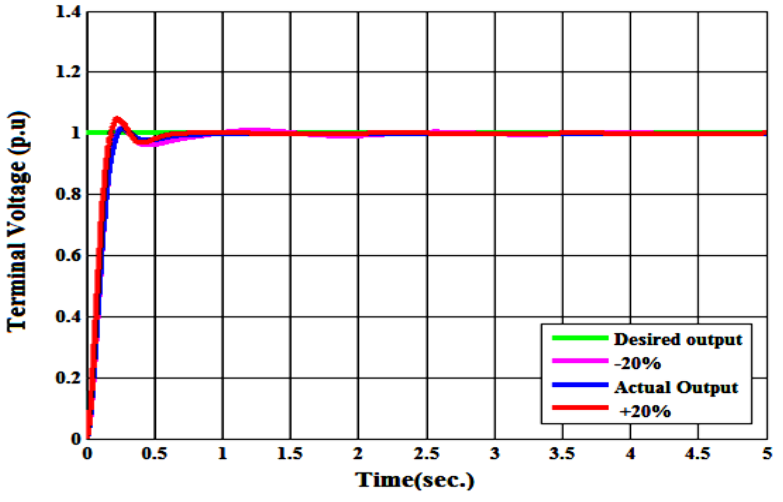

(b)

Figure 8. (a) when changing the time constant of amplifier part with $\pm 20 \%$ from its original value and (b) when changing the gain constant of amplifier part with $\pm 20 \%$ from its original value

From Figure 8 above the effect of changing the time and gain constants of the amplifier part appears on the behavior of the AVR system but it is clear that when changing the time the system needs 1 sec to return to its desired value while changing its gain value is returned to the desired value after $0.7 \mathrm{sec}$ this reflects the robustness of the system controlled using the proposed optimal FOPID controller. 


\section{CONCLUSION}

This paper presents a robust FOPID controller to control the AVR system using a smart parameter tuning algorithm based on WOA that minimizing the error and tracking the desired response, a comparison with the classical PID controller tuned with different methods and with other controllers like fuzzy PI and fuzzy 2 PI. The robustness analysis is utilized in two ways the first one is done by adding disturbances signal in different values and different time during simulating the AVR system, the proposed controller solve this issue and reject these signals then return to the stable behavior of the system within short period efficiently and the second way is by changing the system parameters with $\pm 20 \%$ from its original value to test the system behavior based on this change, the system suffers from low overshoot but its reach desired value in a time range between (0.7-1) sec.

\section{REFERENCES}

[1] N. K. Ray, S. K. Mohapatra and S. S. Dash, "Gravitational Search Algorithm for Optimal Tunning of controller parameters in AVR system," 2020 International Conference on Computational Intelligence for Smart Power System and Sustainable Energy (CISPSSE), 2020, pp. 1-6, doi: 10.1109/CISPSSE49931.2020.9212197.

[2] K. P. Mohanty, B. K. Sahu, and S. Panda, "Tuning and assessment of proportional-integral-derivative controller for an automatic voltage regulator system employing local Unimodal Sampling Algorithm," Electric Power Components and Systems, vol. 42, no. 9, pp.959-969, 2014, doi: 10.1080/15325008.2014.903546.

[3] E. Çelik, "Incorporation of stochastic fractal search algorithm into efficient design of PID controller for an automatic voltage regulator system," Neural Computing and Applications, vol. 30, no. 6, pp.1991-2002, 2018, doi: 10.1007/s00521-017-3335-7.

[4] M. A. Sahib, "A novel optimal PID plus second order derivative controller for AVR system," Engineering Science and Technology an International Journal, vol.18, pp.194-206, 2015, doi: 10.1016/j.jestch.2014.11.006.

[5] B. Ozgenc, M. S. Ayas and I. H. Altas, "A Hybrid Optimization Approach to Design Optimally Tuned PID Controller for an AVR System," 2020 International Congress on Human-Computer Interaction, Optimization and Robotic Applications (HORA), 2020, pp. 1-5, doi: 10.1109/HORA49412.2020.9152898.

[6] A. Sikander and P. Thakur, "A new control design strategy for automatic voltage regulator in power system," ISA transactions, vol. 100, pp. 235-243, 2020, doi: 10.1016/j.isatra.2019.11.031.

[7] B. Hekimoğlu and S. Ekinci, "Grasshopper optimization algorithm for automatic voltage regulator system," 2018 5th International Conference on Electrical and Electronic Engineering (ICEEE), 2018, pp. 152-156, doi: 10.1109/ICEEE2.2018.8391320.

[8] I. A. Khanet, et al., "Salp swarm optimization algorithm-based fractional order PID controller for dynamic response and stability enhancement of an automatic voltage regulator system," Electronics, vol. 8, no. 12, p. 1472, 2019, doi: 10.3390/electronics8121472.

[9] M. Ćalasan, M. Micev, Z. Djurovic, and H. Abdelmegeed, "Artificial ecosystem-based optimization for optimal tuning of robust PID controllers in AVR systems with limited value of excitation voltage," International Journal of Electrical Engineering Education, vol.13, p.0020720920940605, 2020, doi: 10.1177/0020720920940605.

[10] J. Bhookya and R. K. Jatoth, "Optimal FOPID/PID controller parameters tuning for the AVR system based on sinecosine-algorithm," Evolutionary Intelligence, vol. 2, no. 2, pp. 725-733, 2019, doi: 10.1007/s12065-019-00290-x.

[11] J. Sun, L. Wu and X. Yang, "Optimal Fractional Order PID Controller Design for AVR System Based on Improved Genetic Algorithm," 2020 IEEE International Conference on Advances in Electrical Engineering and Computer Applications( AEECA), 2020, pp. 351-355, doi: 10.1109/AEECA49918.2020.9213473.

[12] B. Bourouba, S. Ladaci, and H. Schulte, "Optimal design of fractional order PI $\lambda \mathrm{D} \mu$ controller for an AVR system using Ant Lion Optimizer," IFAC-Papers Online, vol. 52, pp. 200-205, 2019.

[13] .A. G. Suribabu and B. T. Chiranjeevi, "Implementation of fractional order PID controller for an AVR system using GA and ACO optimization techniques" IFAC-Papers Online, vol. 49,no.1 ,pp. 456-461,2016, doi: 10.1016/j.ifacol.2019.11.304.

[14] J. Bhookya and R. K. Jatoth, "Improved Jaya algorithm-based FOPID/PID for AVR system," COMPEL-The international journal for computation and mathematics in electrical and electronic engineering, 1 May, 2020, doi: 10.1108/COMPEL-08-2019-0319.

[15] H. Shayeghi, A. Younesi, and Y. Hashemi, "Optimal design of a robust discrete parallel FP+ FI+ FD controller for the automatic voltage regulator system," International Journal of Electrical Power \& Energy Systems, vol. 67, pp. 66-75,2015, doi: 10.1016/j.ijepes.2014.11.013.

[16] M. Modabbernia, B. Alizadeh, A. Sahab, and M. M. Moghaddam, "Designing the Robust Fuzzy PI and Fuzzy Type-2 PI Controllers by Metaheuristic Optimizing Algorithms for AVR System," IETE Journal of Research, pp. 1-15, 2020, doi: 10.1080/03772063.2020.1769510.

[17] B. Hekimoğlu, "Sine-cosine algorithm-based optimization for automatic voltage regulator system," Transactions of the Institute of Measurement and Control, vol. 41, no. 4, pp. 1761-1771, 2019, doi: 10.1177/0142331218811453.

[18] Y. Batmani. and H. Golpîra, "Automatic voltage regulator design using a modified adaptive optimal approach," Electrical Power and Energy Systems, vol. 104, pp. 349-357, 2019, doi: 10.1016/j.ijepes.2018.07.001.

[19] R. Ruchita, R. Kumar, R. Kumar and K. Sharma, "Comparative Analysis of Optimization Techniques for Controlling an AVR System," 2019 International Conference on Recent Advances in Energy-efficient Computing and Communication (ICRAECC), 2019, pp. 1-5, doi: 10.1109/ICRAECC43874.2019.8995130. 
[20] B. A. Obaid, A. L. Saleh, and A. K. Kadhim, "Resolving of optimal fractional PID controller for DC motor drive based on anti-windup by invasive weed optimization technique," Indonesian Journal of Electrical Engineering and Computer Science, vol. 15, no. 1, pp. 95-103,2019, doi: 10.11591/ijeecs.v15.i1.pp95-103.

[21] X. Li, Y. Wang, N. Li, M. Han, T. Yinggan, and F. Liu, "Optimal fractional order PID controller design for automatic voltage regulator system based on reference model using particle swarm optimization," International Journal of Machine Learning and Cybernetics, vol. 8,no. 5, pp.1595-1605,2017, doi: 10.1007/s13042-016-0530-2.

[22] S. Mirjalili and A. Lewis, "The whale optimization algorithm," Advances in engineering software, vol. 95, pp.5167, 2016, doi: 10.1016/j.advengsoft.2016.01.008.

[23] F. S. Gharehchopogh and H. Gholizadeh, "A comprehensive survey: Whale Optimization Algorithm and its applications," Swarm and Evolutionary Computation, vol. 48, pp. 1-24, 2019, doi: 10.1016/j.swevo.2019.03.004.

[24] A. Kumar and S. Suhag, "Whale optimization algorithm tuned fractional order PI $\lambda \mathrm{D} \mu$ controller for load frequency control of multi-source power system," International Journal of Bio-Inspired Computation, vol. 13 no. 4, pp. 209-221, 2019, doi: 10.1504/IJBIC.2019.100153.

[25] M. O. Okwu and L. K. Tartibu, "Metaheuristic Optimization: Nature-Inspired Algorithms Swarm and Computational Intelligence, Theory and Applications," Springer Nature, vol. 927, 2020.

[26] L. H. Abood, E. H. Karam and A. H. Issa, "FPGA Implementation of Single Neuron PID Controller for Depth of Anesthesia Based on PSO," 2018 Third Scientific Conference of Electrical Engineering (SCEE), 2018, pp. 247-252, doi: 10.1109/SCEE.2018.8684186.

\section{BIOGRAPHIES OF AUTHORS}

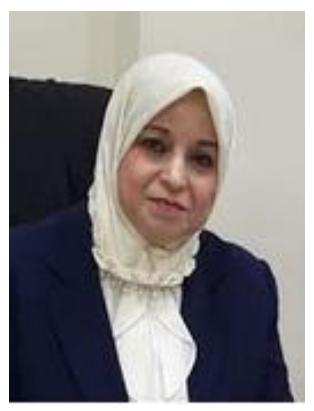

Layla H. Abood received her B.Eng. and M.Sc. and PHD degrees in Electronic and Communication Engineering from the University of Technology-Baghdad. She is currently an Academic staff member in the Department of Control and System Engineering, University of Technology, Baghdad, Iraq Her research interest is Artificial Intelligent, Optimization Technique, Modeling \& Simulation, and FPGA and Embedded systems.

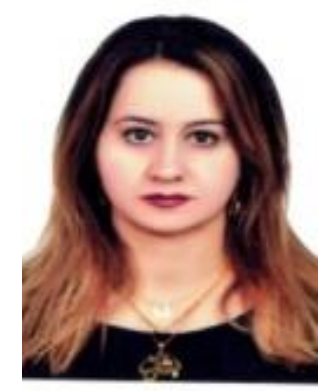

Bashra Kadhim Oleiwi Chabor Alwawi, born in Baghdad-Iraq, completed a Master degree in Mechatronics Engineering/Control and Systems Engineering Department at University of Technology (UOT) Bagdad-Iraq. She finished her $\mathrm{PhD}$ degree at Control Engineering Department (RST), Siegen University, Germany. She is currently working as a faculty member in control and systems engineering department at UOT. My research interests are Deep learning, Machine learning, Artificial intelligence systems, IoT, Optimization, Image processing, Robotics, Path planning, Automation, control, Microcontrollers and Sensors. 